\title{
ПРАКТИЧЕСКИЕ АСПЕКТЫ КОМПЛЕКСНОЙ И КОМИССИОННОЙ СУДЕБНЫХ ЭКСПЕРТИЗ
}

\author{
Катарага О.С., Петкович П.П., Присэкару В.А. \\ Национальный центр судебных экспертиз при Министерстве \\ Юстиции Республики Молдова, \\ Кишинёв, Республика Молдова
}

Вопросы научной и организационно-процессуальной классификации судебных экспертиз продолжают представлять практический интерес и требуют теоретического обоснования. В статье рассмотрены некоторые практические наблюдения по затронутой теме. $B$ статье также проанализированы практические аспекты комплексной и комиссионной судебных экспертиз, проведен сравнительный анализ законодательных баз, изложены предложения по приведению в соответствии с гносеологическими требованиями ряда понятий.

Ключевые слова: комплексная судебная экспертиза, комиссионная судебная экспертиза, многодисциплинарная экспертиза, гносеологический подход.

Обосновывая свои взгляды на проблему, Е.Р.Россинская пишет, что «теоретические основы правового, но не процессуального и научно-организационного обеспечения судебно-экспертной деятельности должны разрабатываться не теорией судебной экспертизы (здесь, безусловно, правы и Т.В. Аверьянова, и Р.С. Белкин), а именно судебной экспертологией - наукой о судебной экспертизе, в то время как процессуальные аспекты остаются в ведении наук процессуального права. Таким образом, говоря об изучении закономерностей судебно-экспертной деятельности, в целом нельзя оставить в стороне изучение закономерностей единого правового и организационного обеспечения этой деятельности, независимо от вида процесса» [1, с. 181].

Что такое комплексная экспертиза? Рассмотрим на примере процессуальных законов Российской Федерации и Республики Молдова, определения по данному виду экспертизы. Законодательные акты РФ, предусматривают комплексную судебную экспертизу - как экспертизу, в производстве которой участвуют эксперты разных специальностей (ч. 1 ст. 201 Уголовно-процессуального кодекса Российской Федерации (УПК РФ), ч. 1 ст. 85 Арбитражного процессуального кодекса Российской Федерации (АПК РФ)). Аналогичное определение содержится в ст. 23 Федерального закона «О государственной судебно-экспертной деятельности В Российской Федерации» (ФЗ о ГСЭД). В ч. 1 ст. 82 Гражданского процессуального кодекса Российской Федерации (ГПК РФ) закреплено, что комплексная экспертиза назначается судом, если установление обстоятельств по делу требует одновременного проведения исследований с использованием различных областей знания или с использованием различных научных направлений в пределах одной области знания.

В Постановлении Пленума ВС о судебной экспертизе по уголовным делам указано, что в необходимых случаях, когда исследование выходит за пределы компетенции одного эксперта или комиссии экспертов, в соответствии со ст. 201 УПК РФ может быть назначено производство

Адрес для корреспонденции: Катарага Ольга.Семеновна, директор Национального центра судебных экспертиз при Министерстве Юстиции Республики Молдова, докторант университета Бабеша-Бойяи,Клуж Напока, Румыния, тел: +37369101253, e-mail: olea.cat@mail.ru 
комплексной экспертизы, осуществляемой несколькими экспертами на основе использования разных специальных знаний (п. 12). Эксперты при этом составляют совместное заключение, в котором должно быть указано, какие исследования провел каждый эксперт, какие факты лично он установил и к каким пришел выводам. Каждый эксперт, участвующий в производстве комплексной экспертизы, подписывает ту часть заключения, которая содержит описание проведенных им исследований, и несет за нее ответственность (ст. 23 ФЗ о ГСЭД, ч. 2 ст. 201 УПК РФ, ч. 2 ст. 85 АПК РФ). Промежуточные выводы, фрормулируемые этими экспертами, находят свое отражение в исследовательской части заключения.

Эксперты, компетентные в оценке полученных результатов, на основании проведенных исследований и промежуточных выводов фрормулируют в синтезирующей части (наличие которой является особенностью заключения, составляемого после проведения комплексной экспертизы) общий вывод и имеют право подписать общее заключение. Последнее положение закреплено в ФЗ о ГСЭД (ст. 23), АПК РФ (ч. 3 ст. 85) и ГПК РФ (ч. 2 ст. 82), но отсутствует в УПК РФ, что служит поводом к высказыванию критических замечаний. Ю.Г. Корухов по этому поводу пишет: «При такой редакции статья теряет свой смысл. Озаглавив ст. 201 «Комплексная судебная экспертиза», законодатель выхолостил из ее содержания самое главное - возможность комплексирования экспертами разных специальностей полученных ими результатов» [2].

Согласно законодательству Республики Молдова, комплексную экспертизу определяют по степени сложности, а именно: «по сложности сведений из области науки, использованных при производстве судебных экспертиз, они подразделяются на моноспециализированные и комплексные» [3, ч.4, ст.27, п.5]. Ниже перечислены некоторые процессуальные требования:

- комплексная экспертиза производится в случае, когда для разъяснения фактов или обстоятельств дела требуются знания из нескольких областей науки, техники и иных областей человеческой деятельности одновременно;

- комплексная экспертиза может производиться либо комиссией экспертов, квалифицированных для различных видов экспертизы, либо одним экспертом, квалифицированным по нескольким видам экспертизы;

- каждый эксперт-участник комплексной экспертизы проводит исследования в пределах своей компетенции. Эксперт участвует в составлении ответов только на те вопросы акта о назначении экспертизы, которые соответствуют его специализации;

- организация комплексных исследований поручается руководителю публичного судебноэкспертного учреждения или одному из экспертов, включенному в комиссию, созданную для проведения комплексных исследований, которого назначил руководитель публичного судебно-экспертного учреждения.

По итогам производства комплексной экспертизы составляется единое экспертное заключение, в котором указываются исследования, проведенные каждым из экспертов, объем исследований, эксперты, сорормулировавшие ответы на поставленные вопросы, и выводы, к которым они пришли. Заключение судебной экспертизы подписывается судебным экспертом только в части, относящейся к исследованиям, которые он проводил [3, ч. 4, ст.35, п.5].

Согласно теории о судебной экспертизе, комплексная экспертиза - это экспертиза, при производстве которой решение вопроса невозможно без одновременного совместного участия специалистов из различных областей знания для фрормулирования общего вывода. Комплексная экспертиза предопределяется общностью вещественных доказательств, а главным ее признаком 
является решение пограничных вопросов разного рода экспертиз.

Комплексное исследование может проводиться и в рамках экспертизы одного рода или вида («моноэкспертизы») при исследовании одних и тех же объектов разными методами, однако такое исследование не является комплексной экспертизой, поскольку выполняется с использованием комплекса методов в рамках методики одного и того же рода (вида) судебной экспертизы (или точнее - в рамках одной экспертной специальности).

Таким образом, любая комплексная экспертиза представляет собой комплексное исследование, но не любое комплексное исследование является комплексной экспертизой.

Строго говоря не является комплексной экспертизой и исследование одних и тех же объектов (группы объектов) экспертами разных специальностей для решения вопросов, относящихся к разным родам экспертиз, если экспертами, эти вопросы решены без совместных исследований и оценки полученных результатов. В этом случае речь идет о комплексе экспертиз (многоспециализированной экспертизе).

Следует признать, что комплексный характер экспертизы не определяется лишь единством исследуемого объекта. В законодательстве Республики Молдова, понятия «комплексная экспертиза» и «комплексное исследование» сфрормулированы ошибочно, без учета раскрытых выше их принципиальных различий.

В настоящее время дискуссионным является также вопрос об обязательной комиссионности комплексной экспертизы. Как уже было указано выше, в процессуальных Кодексах и в Ф3 о ГСЭД РФ закреплено, что комплексная экспертиза должна производиться несколькими экспертами (комиссией). Поэтому вопрос состоит в следующем: следует ли законодательно закрепить возможность проведения единоличной комплексной экспертизы? Утвердительный и отрицательный ответы основываются на сложившихся двух различных взглядах на природу комплексной экспертизы.

В соответствии с законодательными положениями Республики Молдова, при производстве комплексной экспертизы, комиссионность не является обязательным, возможно и проведение одним экспертом, в случае если он обладает необходимыми экспертными специальностями [3, ч.4,ст.25,п.2].

В Российской Федерации первый шаг на пути законодательного закрепления возможности единоличного проведения комплексной экспертизы сделан в Постановлении Пленума ВС о судебной экспертизе по уголовным делам пункт 12 которого изложен следующим образом: «если эксперт обладает достаточными знаниями, необходимыми для комплексного исследования, он вправе дать единое заключение по исследуемым им вопросам» [2].

Учёные - исследователи данного вопроса, высказывают в основном две точки зрения относительно комиссионности комплексной экспертизы.

Так, согласно одной точке зрения, комплексная экспертиза - это в первую очередь правовое понятие, поскольку закрепление в уголовно-процессуальном законодательстве указанных выше особенностей ее назначения и производства обеспечивает прежде всего достоверность выводов, получаемых несколькими экспертами разных специальностей в результате проведения совместного исследования. Особая процедура проведения комплексной экспертизы решает возникающую при ее производстве проблему личной ответственности эксперта за проведенные исследования.

Другая точка зрения исходит из того, что категория комплексности должна пониматься с позиции гносеологии, то есть основной признак комплексной экспертизы заключается в том, что 
при ее проведении происходит интеграция знаний разных родов судебных экспертиз.

История развития законодательного регулирования института судебных экспертиз разных стран, свидетельствует о том, что характер экспертного обеспечения расследования и рассмотрения дел претерпевают не только «количественные» изменения (расширение возможности использования специальных знаний, вовлечение новых объектов в сферу экспертного исследования, приобретение знаниями, ранее считавшимися «общеизвестными», статуса «специальных»), но и «качественные» изменения. Последнее, в частности, выражается во взаимопроникновении методов разных родов судебных экспертиз, что позволяет дать суду и следствию наиболее полную информацию об интересующих их объектах.

Действительно, в тех случаях, когда несколько экспертов, обладающих разными специализациями, производят одну экспертизу, требуется особый порядок, обеспечивающий формулирование объективного общего вывода и соблюдение компетенции каждого эксперта. Однако в такой особой процессуальной форме отпадает необходимость, если эксперт достаточно компетентен, чтобы произвести комплексную экспертизу самостоятельно: он будет нести ответственность за все проведенное им исследование и за все сделанные на его основе выводы. Такое комплексное исследование, как и при комплексном исследовании в рамках «моноэкспертизы», не порождает процессуальных проблем и не имеет процессуальных особенностей.

Российские исследователи по данному вопросу, приводят предложения законодательного характера, рекомендуя следующую редакцию изложения ст. 201 УПК РФ «Комплексная судебная экспертиза:

1. Судебная экспертиза, производство которой поручено экспертам разных специальностей или эксперту, обладающему двумя или более экспертными специальностями, является комплексной.

1. Если комплексную судебную экспертизу проводит комиссия экспертов разных специальностей, то в заключение экспертов указывается, какие исследования и в каком объеме провел каждый эксперт, какие фракты он установил и к каким выводам пришел. Каждый эксперт, участвовавший в производстве комплексной судебной экспертизы, подписывает ту часть заключения, которая содержит описание проведенных им исследований, и несет за нее ответственность. Общий вывод делают эксперты, компетентные в оценке полученных результатов и формулировании данного вывода. Если основанием общего вывода являются фракты, установленные одним или несколькими экспертами, это должно быть указано в заключении. В случае возникновения разногласий между экспертами каждый из них или эксперт, который не согласен с другими, дает отдельное заключение.

1. Если эксперт обладает достаточными знаниями, он вправе провести комплексную экспертизу единолично. В этом случае он дает заключение только от своего имени и единолично несет за него ответственность» [2].

Хочется отметить, что с точки зрения гносеологических положений, по нашему мнению, следует пересмотреть предложенный формат статьи в плане положений о формулировании выводов [4]. При этом необходимо учитывать особенности комплексной экспертизы в части роли экспертов, их научной и процессуальной компетенции. В данном случае следует очень четко разграничить полномочия в их действиях, в зависимости от специальностей и последовательности проводимых исследований в рамках экспертизы. 
Теория различает, две «ролевые функции» выполняемые судебными экспертами при производстве комплексной экспертизы:

- эксперты, которые в результате проводимых ими исследований участвуют в формулировании промежуточных выводов;

- эксперты, роль которых заключается в интегрировании промежуточных выводов и формулировании основных, по сути ответов на поставленные вопросы.

Также, необходимо учесть, что комплексный характер данного рода экспертиз выражается и в необходимости одновременного применения специальных знаний и пограничных областей науки и техники или ремесла, для решения экспертных задач. Таким образом, каждый эксперт проводит, исключительно исследования согласно своей компетенции в рамках его экспертной специальности, и приводит в заключении свои промежуточные выводы, за которые и несет полную ответственность. Интегратор же, оценивая промежуточные выводы, фрормулирует основной вывод за который и несет ответственность. Данные обобщения вытекают из самого процесса производства комплексной экспертизы и, естественно, требуют законодательного закрепления. Следует добавить, что основанием для различия однородных и комплексных экспертиз в таком случае следует считать не состав исполнителей, а состав применяемых специальных знаний.

Учитывая вышеизложенное, становится очевидным, что основной вывод может быть сорормулирован, но при этом ответственность полностью ляжет только на эксперт-интегратора. Если в роли интеграторов выступают несколько экспертов, то следует применять процессуальные положения относительно комиссионной экспертизы, когда каждый эксперт формулирует свои выводы (при имеющихся разногласиях). Данный случай, законодателем не учтен (также данный подход не учтен и в предложенной новой редакции статьи) и возникает коллизия, что каждый эксперт может приводить свои выводы. На самом деле, эксперты, участвующие в промежуточных исследованиях, не имеют компетенцию делать основной вывод, так как не обладают знаниями в полном объеме. Следовательно, не совсем понятно, каким образом положения законов (РФ и РМ) о том, что каждый эксперт может делать свой вывод, при проведении комплексной экспертизы могут быть выполнены.

Считаем важным отметить, что комплексная экспертиза может иметь так же и комиссионный характер.

К примеру, так как, на практике процессуалисты и некоторые судебные эксперты часто путают различия между комплексной и комиссионной экспертизами, нередко возникают проблемы, как при назначении, так и при выполнении аналогичных экспертиз.

Рассматривая законодательные положения по комиссионным экспертизам (УПК РФ, УПК РМ), можно констатировать, что на первый взгляд как будто бы все предельно ясно, так как комиссионная судебная экспертиза производится не менее чем двумя экспертами одной специальности. Комиссионный характер экспертизы определяется следователем, либо руководителем экспертного учреждения, которому поручено производство судебной экспертизы. Для случаев, когда по результатам проведенных исследований мнения экспертов по поставленным вопросам совпадают, то ими составляется единое заключение. В случае возникновения разногласий каждый из экспертов, участвовавший в производстве судебной экспертизы, дает отдельное заключение по вопросам, вызвавшим разногласия» [4, гл.27, ст.200]. Одновременно с этим, судебные экспертизы повышенной степени сложности или объемные 
судебные экспертизы производятся комиссией из нескольких экспертов одной специализации или, по обстоятельствам, разных специализаций. По ходатайству сторон в состав экспертной комиссии могут быть включены приглашенные (рекомендованные) ими эксперты. Комиссионная судебная экспертиза назначается и в случае, если ранее проведенные судебные экспертизы привели к неоднозначным выводам. В рамках комиссионной судебные экспертизы могут ставиться вопросы, касающиеся причин расхождений в выводах предшествующих судебных экспертиз. В конце исследований в рамках комиссионной судебной экспертизы составляется общее заключение судебной экспертизы, которое подписывается всеми входящими в состав комиссии экспертами. В случае отсутствия общего вывода, с которым согласились бы все эксперты, в заключении судебной экспертизы представляется вывод, выражающий единое мнение большинства экспертов, принимавших участие в производстве комиссионной судебной экспертизы, или сообщается о невозможности представления общего вывода. Особые мнения экспертов излагаются в отдельных заключениях, которые прилагаются к экспертному заключению и также представляются заказчику судебной экспертизы.

Следует подчеркнуть, что требование органа уголовного преследования, прокурора или судебной инстанции о производстве судебной экспертизы комиссией экспертов является обязательным для руководителя экспертного учреждения, а также для назначенных экспертов. Если судебная экспертиза поручается экспертному учреждению и его руководитель, исходя из сложности предстоящих исследований, считает необходимым произвести комиссионную судебную экспертизу, он предлагает органу уголовного преследования, прокурору или судебной инстанции назначить производство таковой» [5, ч.7, ст.146].

Хотя редакция, изложенная в УПК РФ, не вызывает возражений, следует отметить, что на наш взгляд не совсем правильно выдавать несколько заключений (в случае разногласий экспертов), т.к. разногласия могут возникнуть на разных этапах экспертного исследования. Когда исследования излагаются в едином документе, разграничивая действия, результаты, оценки и мнения экспертов, при наличии разногласий, документ (заключение эксперта) представляет более значимое с научной, и думается, что и с процессуальной точки зрения доказательство.

Изучая практику назначения и выполнения комиссионных экспертиз, следует отметить два основных подхода. Первый из них основан на мнении, что основным мотивом при вынесении определения о назначении комиссионной экспертизы является повышение внутренней убежденности судьи в достоверности будущего проведенного исследования. Считается, что если экспертиза проведена не одним, а двумя и более экспертами, то она будет более обоснованной и объективной. В соответствии с законодательством, эксперты не могут разделить исследования на этапы и выполнять каждый свою часть. Комиссионная экспертиза - это судебная экспертиза, которая проводится двумя и более экспертами, имеющими единое направление знаний. В большинстве случаев проведение экспертизы поручают нескольким экспертам, потому что процесс это довольно сложный и трудоемкий. Каждый эксперт должен проводить исследования в полном объеме и в установленном порядке. Это необходимо для того, чтобы выводы после анализа исследований были абсолютно объективными [6]. Второй подход намного проще, и рассматривает комиссионную экспертизу, как экспертизу которую проводят несколько экспертов [5, ст.146, п.1].

Обе точки зрения, считаем предвзятыми, поскольку ни одна, ни другая не учитывают комплекс отличительных характеристик комиссионной экспертизы, а именно:

- комиссионная судебная экспертиза производится не менее чем двумя экспертами в одной 
области знаний (в пределах одного научного направления) в целях дачи более объективного заключения, ускорения проведения экспертизы. При производстве комиссионной судебной экспертизы экспертами одной специальности каждый из них проводит исследования в полном объеме, и они совместно анализируют полученные результаты. Каждый эксперт, участвующий в проведении комиссионной экспертизы, при наличии разногласий с другими, имеет право представить свои результаты и выводы, за которые несет в полной мере ответственность. В составе комиссии экспертов, которой поручено производство судебной экспертизы, каждый эксперт независимо и самостоятельно проводит исследования, оценивает результаты, полученные им лично и другими экспертами, и формулирует выводы по поставленным вопросам в пределах своих специальных знаний. Один из экспертов указанной комиссии может выполнять роль эксперта-организатора, однако его процессуальные функции не отличаются от фуннций остальных экспертов.

Таким образом, предложенный нами подход к процессу проведения комиссионной судебной экспертизы обеспечивает соблюдение в полной мере важнейших принципов судебно-экспертной деятельности: принципа независимости и принципа объективности и полноты исследований. В то же время достигается цель повышения объективности выводов экспертов, т.к. выводы сорормулированы несколькими экспертами одной специальности.

Часто встречается мнение, что комиссионная экспертиза может быть проведена и экспертами разных специальностей, и это даже закреплено законом. Думается, что это не совсем правильно с гносеологической точки зрения. В подтверждение нашего мнения приведем следующие соображения. Чаще всего, комиссионная экспертиза выполняется для установления какихлибо обстоятельств, имеющих процессуальное значение при вынесении решения, в случае возникновения сложностей в разрешении вышеуказанных обстоятельств, которые единоличная экспертная оценка не может установить, и требует привлечения одновременно нескольких специалистов одной области для решения задачи, которую не смог решить один специалист. Для ситуаций, когда в комиссию входят специалисты из разных областей, каждый будет решать исключительно вопросы в пределах своей компетенции. Таким образом, главную процессуальную цель комиссионной экспертизы - получение более объективных выводов (когда выводы формулируется несколькими экспертами одной специальность) невозможно достичь, так как специалисты владеют разными специальностями. В данном случае имеем сумму нескольких единоличных экспертиз, заключенных в одном процессуальном документе, но ни как ни одну комиссионную экспертизу. При производстве «комиссионной» судебной экспертизы экспертами разных специальностей, каждый из них не может проводить исследования в полном объеме, так как не владеет всеми требуемыми специальностями и следовательно они так же совместно не могут анализировать полученные результаты. Такой подход никак не объясняет и возможность представления экспертами отдельных результатов (при наличии разногласий), так как их в принципе не может быть, ввиду того, что судебные эксперты имеют изначально разные компетенции.

С учетом вышеизложенного, предлагаем для данных случаев использовать термин «многодисциплинарная экспертиза», так как именно он отражает в полной мере процесс производства экспертиз несколькими экспертами разных специальностей. Многодисциплинарная экспертиза может проводиться и одним экспертом, если он обладает всеми необходимыми специальностями для решения поставленных задач, либо несколькими экспертами, специалистами 
в соответствующих областях. При этом необходимо отметить, что отличительной чертой многодисциплинарной экспертизы от комиссионной и комплексной является то, что ее можно разделить на несколько единоличных экспертиз. Таким образом, отталкиваясь от изложенного материала, можно определить следующие отличительные характеристики по классификации судебных экспертиз.

Таблица 1

\section{Отличительные характеристики по классификации судебных экспертиз}

\begin{tabular}{|c|c|c|c|c|}
\hline & Характерные черты & $\begin{array}{l}\text { Комиссионная } \\
\text { экспертиза }\end{array}$ & Комплексная экспертиза & $\begin{array}{c}\text { Многодисциплинарная } \\
\text { экспертиза }\end{array}$ \\
\hline 1 & Цели & $\begin{array}{c}\text { 1.Решение задач, с } \\
\text { которыми не справились } \\
\text { единоличные } \\
\text { экспертизы } \\
\text { 2. Получение более } \\
\text { объективных выводов }\end{array}$ & $\begin{array}{c}\text { Решение задач требует } \\
\text { одновременного } \\
\text { использования знаний из } \\
\text { разных областей науки }\end{array}$ & $\begin{array}{c}\text { Решение задач из разных } \\
\text { областей науки }\end{array}$ \\
\hline 2 & $\begin{array}{c}\text { Количество } \\
\text { используемых } \\
\text { областей знаний }\end{array}$ & Одна & $\begin{array}{c}\text { Несколько пограничных } \\
\text { областей знаний }\end{array}$ & Не менее двух областей \\
\hline 3 & $\begin{array}{l}\text { Количество } \\
\text { экспертов }\end{array}$ & Не менее двух & Один или более одного & Один или более одного \\
\hline 4 & $\begin{array}{c}\text { Разделение } \\
\text { экспертов по ролям }\end{array}$ & $\begin{array}{l}\text { Эксперт-организатор } \\
\text { (нет процессуальных } \\
\text { отличий от остальных) }\end{array}$ & $\begin{array}{c}\text { Эксперт-интегратор- } \\
\text { обладает специальностью } \\
\text { необходимой для дачи } \\
\text { финальных выводов }\end{array}$ & $\begin{array}{c}\text { Эксперт-координатор (нет } \\
\text { процессуальных отличий } \\
\text { от остальных) }\end{array}$ \\
\hline 5 & $\begin{array}{c}\text { Формулирование } \\
\text { финальных } \\
\text { выводов } \\
\end{array}$ & Все эксперты & Эксперт-интегратор & $\begin{array}{c}\text { Каждый эксперт } \\
\text { подготавливает свой } \\
\text { вывод } \\
\end{array}$ \\
\hline 6 & $\begin{array}{c}\text { Процессуальная } \\
\text { ответственность } \\
\text { экспертов }\end{array}$ & $\begin{array}{c}\text { Одинаковая, все несут } \\
\text { полную ответственность } \\
\text { за проведенные } \\
\text { исследования (в } \\
\text { полном объеме) и } \\
\text { сформулированные } \\
\text { выводы }\end{array}$ & $\begin{array}{c}\text { Эксперт-интегратор } \\
\text { несет ответственность } \\
\text { за исследования по } \\
\text { интеграции и финальному } \\
\text { выводу. } \\
\text { Все остальные эксперты } \\
\text { - за свои исследования и } \\
\text { промежуточные выводы } \\
\end{array}$ & $\begin{array}{c}\text { Каждый эксперт } \\
\text { несет ответственность } \\
\text { за проведенные } \\
\text { исследования и } \\
\text { сфрормулированные им } \\
\text { выводы }\end{array}$ \\
\hline 7 & $\begin{array}{c}\text { Возможность } \\
\text { разделения на } \\
\text { единоличные } \\
\text { экспертизы }\end{array}$ & $\begin{array}{c}\text { Имеется при наличии } \\
\text { разногласий с другими } \\
\text { экспертами }\end{array}$ & Нет & $\begin{array}{l}\text { Имеется по каждой } \\
\text { из экспертных } \\
\text { специальностей }\end{array}$ \\
\hline
\end{tabular}

И в заключение, мы считаем важным еще раз подчеркнуть, что с нашей точки зрения, более корректным является гносеологический подход к определению понятий «комплексная экспертиза», «комплексное исследование», «комиссионная экспертиза», а также использование данного подхода для термина «многодисциплинарная экспертиза». При этом, этот подход позволит избежать возможных ошибок как со стороны судебных экспертов - исполнителей, так и со стороны правоохранительных органов назначающих судебные экспертные исследования.

\section{Список литературы}

1. Россинская Е.Р. Унификация законодательства о судебной экспертизе: реальность или иллюзия // Судебная экспертиза в парадигме Российской науки (к 85-летию Ю.Г.Корухова), Материалы 
54-х криминалистических чтений. Ч. 2. М., 2013.

2. https://ceur.ru/news/item133588/.

3. Закон № 68 от 14.04.2016 г. «о судебной экспертизе и статусу судебного эксперта», опубликован в Офрициальном Мониторе Молдовы № 157-162 от 10.06.2016, ст.316.

4. «Уголовно-процессуальный кодекс Российской Федерации» от $18.12 .2001 \mathrm{~N} 174-Ф 3$ (ред. от 20.07.2020).

5. Уголовно-процессуальный кодекс Республики Молдова от 14 марта 2003 года № 122-XV. (с изменениями и дополнениями по состоянию на 12.02.2021г.)

6. https://martinforaz.com/grazhdanskoe-pravo/komissionnaya-ekspertiza-osobennosti.php

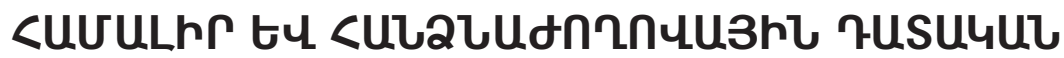

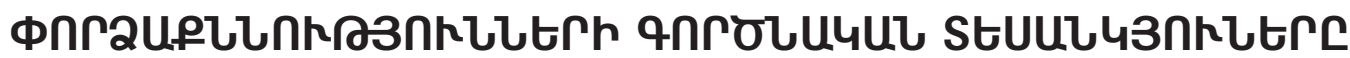

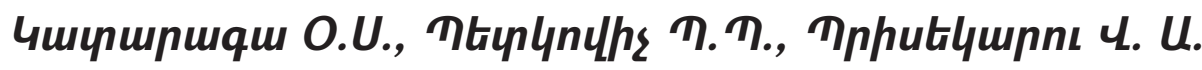

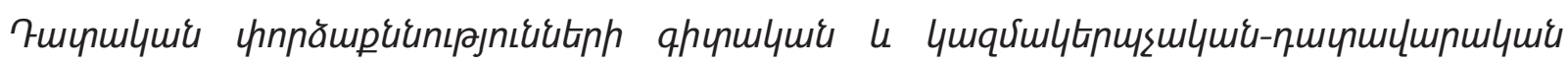

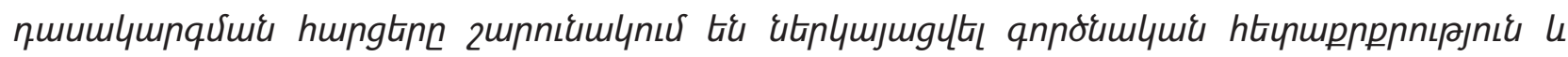

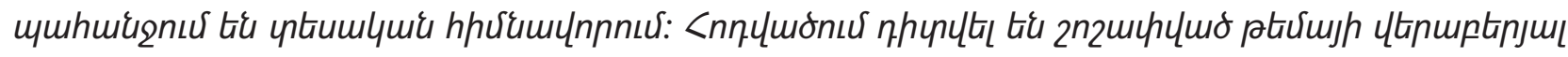

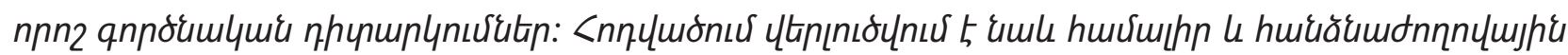

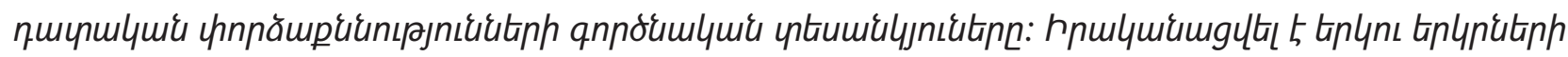

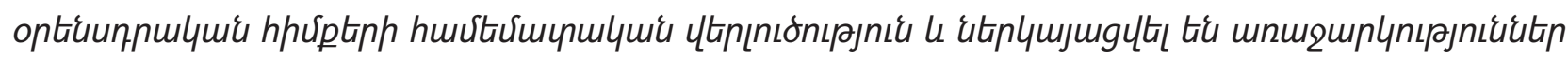

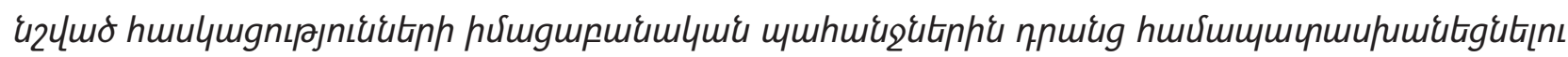
unnouny:

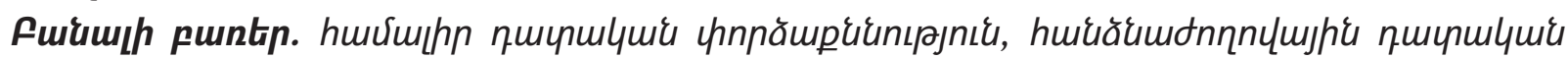

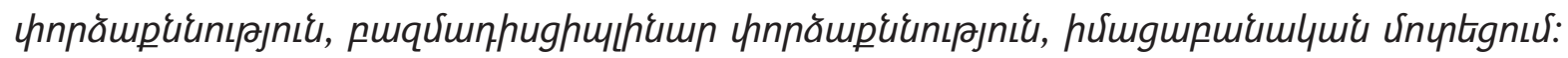

\section{PRACTICAL ASPECTS OF COMPLEX AND COMMISSION FORENSIC EXPERTISE}

\section{Cataraga O., Petkovich P., Prisakaru V.}

The issues of scientific and organizational-procedural classification of forensic expertise continue to be of practical interest and require theoretical justification. The article discusses some practical observations on the topic addressed. The article also analyzes the practical aspects of a comprehensive and commission forensic expertise. A comparative analysis of the legislative bases of the two countries was carried out and proposals for their adjustment in accordance with the epistemological requirements of these concepts were presented.

Key words. complex forensic expertise, commission forensic expertise, multidisciplinary expertise, epistemological approach.

Статья поступила: 19.09.2020

Принята к печати: 10.04.2021 